
\title{
David Cronenberg e a Escola de Toronto: as extensões sombrias da máquina
}

\section{David Cronenberg and the Toronto School: gloomy extensions of the machine}

\section{André Azevedo da Fonseca}

Professor Adjunto de Mestrado em Comunicação na Universidade Estadual de Londrina.

Doutor em História pela Universidade Estadual Paulista com pós-doutorado no Programa Avançado em Cultura Contemporânea da Universidade Federal do Rio de Janeiro.

E-mail: azevedodafonseca@gmail.com

\section{Andreza Lisboa da Silva Fernandes}

Mestre em Comunicação pela Universidade Estadual de Londrina. Graduada em Comunicação Social/Jornalismo pela Universidade Federal de Sergipe.

E-mail: drecas.slv@gmail.com

Recebido em 10 de dezembro de 2015. Aprovado em 20 de junho de 2016.

\section{Resumo}

A obra do cineasta David Cronenberg propõe uma visão sombria das tecnologias ao ressaltar os aspectos grotescos da simbiose entre ser humano e máquina. $\mathrm{O}$ objetivo desta pesquisa foi analisar as relações entre o cinema de Cronenberg e a perspectiva teórica da Escola de Toronto. A análise fílmica de Videodrome foi usada em conjunto com a crítica do pensamento de Harold Innis e Marshall McLuhan. A conclusão é a de que Cronenberg problematiza a noção das tecnologias como extensões do corpo humano, e formula um contraponto original nessa reflexão no campo das teorias da comunicação.

Palavras-chave: Imaginários tecnológicos. David Cronenberg. Escola de Toronto. 


\section{Abstract}

David Cronenberg's work proposes a gloomy view of technology by highlighting the grotesque aspects of the symbiosis between human and machine. The objective of this research was to analyze the relationship between Cronenberg's films and the theoretical perspective of the Toronto School. The film analysis of Videodrome and the critical thinking of Harold Innis and Marshall
McLuhan were used together. The conclusion is that Cronenberg problematize the notion of technologies as extensions of the human body, and makes a unique counterpoint in this reflection on the communication theories field.

Keywords: Technological imaginary. David Cronenberg. Toronto School.

\section{Introdução}

Projeções de cenários fantásticos, criaturas pitorescas de origem extraterrena ou fantasias desligadas do atual contexto histórico definitivamente não fazem parte dos temas do cineasta canadense David Cronenberg. Quem espera por essas caracterizações, costumeiramente associadas aos blockbusters de ficção científica, surpreende-se ao constatar o quão longe ele passa dos lugares-comuns reproduzidos em filmes de Hollywood.

As primeiras produções de longa-metragem realizadas por Cronenberg foram os filmes Stereo (1969) e Crimes do Futuro (1970), obras concebidas em um formato experimental, com cenário delimitado, elenco enxuto e poucos figurantes, além de apresentarem um recurso de narração em substituição aos diálogos diretos dos personagens. Seu filme de apelo mais comercial surge em 1975, com o título Shivers, traduzido em português para Calafrios. O roteiro foi todo concebido pelo diretor, já preocupado em manter a integridade conceitual dos filmes que dirigia.

Sob os auspícios do Canadian Film Development Corporation (CFDC), que determinava a destinação dos apoios do fundo de ajuda financeira criado pelo governo do Canadá, o filme demorou três anos para ser concluído, entre o tempo de realização do roteiro até a produção final. Orçado em 180 mil dólares canadenses, Calafrios obteve um retorno financeiro de cinco milhões para os cofres da CFDC e foi distribuído para mais de 40 países, colocando-o como um dos maiores sucessos cinematográfico durante o período.

Entretanto, o entusiasmo nas bilheterias não foi correspondido pela crítica especializada. Muitos escreveram textos furiosos contra o que consideraram uma obra de extremo mau gosto, além de obscena, repugnante e até pornográfica. E o pior de tudo, como argumentavam, era o envolvimento de dinheiro público no investimento de tal infâmia. Como 
notou Breder (2011), o filme despertou uma intensa polêmica na imprensa canadense no que dizia respeito ao próprio estatuto da produção artística nacional e, por consequência, aos critérios empregados no financiamento público de projetos cinematográficos.

A partir de então, Cronenberg ficou definitivamente marcado como um cineasta em proximidade com os gêneros do horror e da ficção científica, algo que seria confirmado em suas obras seguintes, Enraivecida na fúria do sexo (1976), Filhos do medo (1979), Scanners (1981) e Videodrome (1983), que radicalizaram a estética repulsiva que incluía cenas explícitas de mutilação, evisceração e sangramento superabundante.

Excetuando-se Fast Company, um filme sobre automobilismo realizado sob encomenda, os demais são produções que não economizam na estética gore: sangue em esguichos, mutilações, implante de órgãos que degeneram, abdomens que se abrem, cabeças que explodem. É nesta época que Cronenberg começa a consolidar a sua reputação de cineasta "escandaloso", angariando, dentre outros epítetos, o de "mestre do horror venéreo", "rei do gore visceral" e "barão da hemoglobina". (BREDER, 2011, p. 176).

Mas Cronenberg não se define como um diretor representante de um gênero ou enquadrado em um universo temático, mas um cineasta preocupado em construir "uma ferramenta analítica e crítica" (ERNST, 2009), ainda que tenha admitido ser um enfático admirador de diretores do gênero horror - mais por observar uma posição de resistência, de muitos deles, por não se enquadrarem às regras impostas pelo sistema dos grandes estúdios de cinema em Hollywood. Além disso, para ele, o cinema de horror desenvolveu uma tradição em abordar temas controversos, a partir de perspectivas originais e sem a preocupação de se submeter a uma linha narrativa com explicações exclusivamente racionais.

Considerando, portanto, que a obra de Cronenberg uniu ficção científica e horror para discutir as perversões humanas por meio da simbiose entre ser humano e máquina, o objetivo desta pesquisa foi identificar as relações problemáticas entre o cinema de Cronenberg e a perspectiva da Escola de Toronto - da qual o próprio cineasta é tributário, tomando como referência as obras de Marshall McLuhan e sua proposição de tecnologia como extensões do corpo humano.

\section{Procedimentos teóricos e metodológicos}

Analisar um filme, explicam Vanoye e Goliot-Lété (1994), implica essencialmente em decompor seus elementos constitutivos e desconstruir o texto fílmico para obter um 
conjunto de elementos distintos do próprio filme, de acordo com os objetivos da análise. Em seguida, a análise deve buscar os elos entre elementos isolados para compreender "como eles se associam e se tornam cúmplices para fazer surgir um todo significante" (VANOYE; GOLIOT-LÉTÉ, 1994, p. 15).

É importante observar que, se a desconstrução equivale à descrição, a reconstrução corresponde ao que se costuma definir como interpretação. Contudo, como argumentam Vanoye e Goliot-Lété (1994), não é prerrogativa da análise o ato de distinguir cronologicamente e linearmente as duas fases, mas de imbricá-las em uma alternância, evitando naturalmente as fraquezas de se confundir "descrição" com "interpretação", de se perder em fabulações pessoais ou de se comprometer com hipóteses falsas que prejudicam a análise ao induzir o pesquisador a defender noções preconcebidas.

O tratamento aconselhado: em primeiro lugar, desenvolver seu sentido de autocrítica e, por outro lado, permanecer flexível intelectualmente o suficiente para conseguir a todo instante enfrentar um imprevisto e aceitar a mudança de rumo. (Ibid., p. 16).

Analisar um filme é também situá-lo em um contexto. "Um filme jamais é isolado. Participa de um movimento ou se vincula mais ou menos a uma tradição." (Ibid., p. 24). Se um dos contextos possíveis diz respeito às relações do filme com a própria história das formas fílmicas, e tendo em vista a perspectiva do próprio pensamento de Cronenberg entender seu cinema como "uma ferramenta analítica e crítica", é indispensável situar alguns fundamentos teóricos expressos em suas reflexões acerca de seus filmes, sobretudo observando que o cineasta é um leitor declarado do conterrâneo Marshall McLuhan, cuja influência é notável em sua temática. Desse modo, em termos metodológicos, o filme será utilizado para discutir um conceito. Para isso, vamos seguir o procedimento de selecionar "informações parciais, isoladas, do filme para relacioná-las com informações extratextuais". (Ibid., p. 53).

Atualmente, é consensual a noção de que todo texto autoriza uma pluralidade de leituras. Entretanto, é importante definir se essas possibilidades de interpretação são desejadas ou previstas, conscientemente ou não, pelo próprio autor; ou formuladas pela atividade interpretativa do analista, que deve evitar a armadilha de projetar na obra as suas próprias tramas, obsessões e desejos. "A intenção do autor e a do leitor constituem conjeturas, propostas quanto ao que a obra diz: falta examinar em que medida a obra, em sua própria coerência e por ela, aprova, desaprova essas conjeturas, ou indica outras" (Ibid., p. 54).

E por fim, a interpretação simbólica de um filme exige a busca por sentidos que superem a denotação literal das imagens. Essa leitura exige a compreensão do "horizonte 
simbólico" - ou "universo diegético" - que torna o filme plausível e coerente. Os autores alertam que "o sistema metafórico próprio de certos filmes requer uma cultura específica para ser plenamente apreendido" (Ibid., p. 60). No caso de Cronenberg, nota-se que, para penetrar em seus códigos, é indispensável a reflexão sobre a perspectiva teórica da Escola de Toronto e sobretudo a obra do conterrâneo Marshall McLuhan.

A denominação atribuída a McLuhan, "profeta da era eletrônica" ou "oráculo da globalização", deve-se ao tom de antecipação que ele enxergava sobre a incidência da tecnologia no cotidiano das pessoas, refletindo sobre os impactos e modos de uso que viriam a se confirmar nas décadas posteriores.

A centralidade dos media nos seus estudos carrega um discurso afinado com outro teórico canadense, considerado uma influência direta para muitas de suas análises: o economista e historiador Harold Innis. Juntos, eles são marcados como os principais representantes do grupo de pesquisa em comunicação do Canadá, referenciado como a Escola de Toronto. Por essa formação intelectual, iniciada nos anos 1950, uma série de estudos ficou concentrada na materialidade dos efeitos provocados pelos media, e não apenas nos conteúdos das mensagens veiculados por esses aparatos.

A partir de então, como explica Rüdiger (2011), o próprio meio de comunicação é investigado como um agente de transformação sobre as categorias de formação do mundo, como o tempo e espaço, o que incide, de forma patente, na mudança das relações encontradas na sociedade. Ou seja, entender os meios significaria entender as estruturas culturais, as relações de trabalho ou os modos sociais, já que cada objeto técnico apresenta fundamental importância para o encadeamento de transformações mundiais ao longo da história.

Desse ponto de vista, a defesa encabeçada por esses pesquisadores era de que a teoria da comunicação deveria dar lugar a uma teoria dos meios de comunicação - a expressão designada para essa escolha conceitual é medium theory. Sendo assim, em termos epistemológicos, os autores e seguidores dessa linha encaravam a comunicação como "um meio de projeção da consciência e de nossos sentidos, que se reveste de determinadas estruturas técnicas e, assim, modela as formas de nossa sociedade" (RÜDIGER, 2009, p. 123).

O primeiro teórico a trabalhar sobre a relação direta entre tecnologia e o seu impacto nas transformações da perspectiva sociocultural foi Harold Innis, a partir de duas obras significativas: Empire and communications (1950) e The bias of communication (1951). Por elas, deu-se uma especial atenção às tecnologias de comunicação, caracterizadas por sempre carregarem uma influência ou inclinação, por nunca se apresentarem como neutras e exercerem um controle sobre as noções de tempo ou espaço. 
Conforme explica Sousa (2006), por meio dos escritos de Innis chegou-se ao entendimento de que a preferência de um determinado meio em cada sociedade gera uma organização social diferente, já que a comunicação não apenas move as categorias relacionadas ao desenvolvimento econômico dos grupos, mas também move o percurso da própria história.

O legado de Innis é herdado por McLuhan, que declaradamente afirma realizar A galáxia de Gutenberg, lançado em 1962, como um livro de notas explicativas para as obras de seu conterrâneo. Em linhas gerais, o ponto de interesse dos dois autores fica em destaque pela aplicação da técnica no centro dos estudos em comunicação. O resultado de tal posicionamento é uma postura inovadora que vai na contramão das tendências conceituais dessa área.

Um dos grandes aforismos de McLuhan repetido diversas vezes e alvo de grande parte dos que criticam suas ideias se apresenta na expressão "o meio é a mensagem". Por essa síntese conceitual, ele deixa observar que a mensagem do meio está implícita na sua própria configuração tecnológica, na forma como ela promove mudanças de escala, cadência ou padrão quando é introduzida ou se faz presente na vida das pessoas. Ao que ele explica:

Tendo em conta que por mídia não entendo unicamente os mass media (minha definição inclui qualquer tecnologia que crie extensões ao corpo humano e aos sentidos, desde o vestuário ao computador) e considerando que as sociedades sempre estiveram mais condicionadas pela natureza de seus mass media que pela mensagem que estes lhe transmitem, temos então de concluir quando uma nova tecnologia penetra numa sociedade, satura todas as instituições. (MCLUHAN, 1979, p. 9).

Dessa sentença, ele propõe que o conteúdo do meio, na verdade, consiste em outro meio, mostrando alguns exemplos para confirmar sua afirmação, como o conteúdo da escrita ser a fala, a palavra escrita, o conteúdo da imprensa e assim por diante. A precipitação de um meio em outro define, a seu ver, uma mudança no foco de entendimento único da "mensagem" ou, aqui caberia colocar, "programação" desse meio, já que seus efeitos operam independentes do teor que veiculam.

Ao que parece sinal de desprezo ou indiferença ao conteúdo das mensagens dos media, essa reflexão pode ser vista como uma forma de trazer um novo enfoque sobre as instâncias operativas do processo comunicacional. Segundo avalia Pereira (2011), essas afirmativas de McLuhan se direcionavam a uma abertura para a análise do conteúdo das mensagens, em que o meio era posto em evidência em sua total conjuntura, entendendo-o 
como uma nova linguagem capaz de "reformar" toda a cultura. Em um de seus textos, fica perceptível essa questão:

Todos os meios agem sobre nós de modo total. Eles são tão penetrantes que suas consequências pessoais, políticas, econômicas, estéticas, psicológicas, morais, éticas e sociais não deixam qualquer fração de nós mesmos inatingida, intocada ou inalterada. O meio é a massa-gem. Toda compreensão das mudanças sociais e culturais é impossível sem o conhecimento do modo de atuar dos meios como meio ambiente. (MCLUHAN, 1969, p. 54).

O caráter inevitável de uso dos media se confirma, para McLuhan, à medida que os indivíduos continuam consumindo-os independentemente do "conteúdo" dos programas que eles veiculam. A explicação dada para tal fenômeno se manifesta no entendimento que os meios são prolongamentos de um órgão, sentido ou de uma função do corpo humano, sendo que os aparelhos elétricos, reforçados pelas tecnologias de comunicação seguintes à era do impresso, caracterizam-se como uma projeção do sistema nervoso central do indivíduo.

A qualidade de extensão implica também em um processo de "autoamputação" realizado pelo homem para alívio imediato da pressão que os meios exercem sobre seu sistema nervoso central. O resultado dessa "autoamputação" exige uma relação de equilíbrio com os demais órgãos do corpo, o que necessariamente implica na adoção desse extensor diariamente nas rotinas, incorporando-o em um "gesto autoprotetor de entorpecimento da área prolongada" (MCLUHAN, 2012, p. 197).

O estado anestésico ou narcótico de alguém, quando submetido aos meios, caracteriza a aceitação dessas extensões, sem o risco de rejeição ou confronto sobre as mudanças no ambiente advindas do estabelecimento dessa nova tecnologia. A falta de resistência ou incompreensão diante do aparato tecnológico coloca o ser humano em um quadro de admiração ou, indo além, de idolatria para constituições integrantes do seu próprio corpo, responsáveis por provocar mudanças no ambiente que o circunda e nele mesmo.

A atribuição do mito de Narciso serve como analogia para explicar a conjuntura da atual sociedade tecnológica que contempla fascinada os meios como estruturas externas de si, mas na verdade trata-se do próprio ser humano revestido em outra apresentação extensível ou autoamputada. E justamente por essa integração do orgânico com o artificial, estabelece-se uma troca em que o indivíduo vê-se continuamente transformado pela tecnologia, mas ao mesmo tempo encontra novas formas de modificá-la (MCLUHAN, 2012). 
A ocorrência desse sistema de permuta recai na afirmação de que "as extensões humanas são expressões do nosso próprio ser" (MCLUHAN, 2005, p. 341). Assim, a ideia de extensão surge em uma lógica de complementação entre ser humano e tecnologia, na qual se deve considerar o processo de apresentação do objeto e o contexto em que ele se relaciona, a fim de entender como esses elementos se encontram e se atingem mutuamente.

A propriedade de extensão dos meios se relaciona a dois fatores básicos, como aponta Pereira (2011): o primeiro é que os mecanismos extensores tratam-se de dispositivos artificiais, ou seja, são invenções externas ao organismo humano; já o segundo é que elas possuem a capacidade de alterar o sistema ao qual se situam, quando são devidamente ativadas. McLuhan defende que os meios, posicionados dentro de um ambiente social, estimulam a produção de novos hábitos, posturas e comportamentos que mutuamente os transformam tecnicamente, como também a sociedade ao qual se relacionam, e assim por diante.

Da inter-relação que os meios estabelecem entre si e com os seus usuários, o estudioso aponta o surgimento de novos índices relacionais capazes de estender e acelerar a vida sensória humana, ao ponto de afetar os sentidos dos sujeitos de maneira completa, proporcionando novos modelos de subjetividade e despertando um estado inédito de consciência particular. Assim como ele demonstra neste trecho:

Os meios, ao alterar o meio ambiente, fazem germinar em nós percepções sensoriais de agudeza única. O prolongamento de qualquer de nossos sentidos altera nossa maneira de pensar e agir - o modo de perceber o mundo. Quando essas relações se alteram, os homens mudam. (MCLUHAN, 1969, p. 69).

A presença dessas tecnologias permite alterações únicas em cada sentido, assim como na relação mútua que eles estabelecem entre si. O resultado dessa modificação é que quando um dos sentidos se vê elevado ou em alta intensidade de uso - devido ao estímulo de uma tecnologia - passa a atuar de forma anestésica para os outros. O ápice do processo determina o que se denomina como um estado de hipnose, em que um sentido é isolado a fim de anestesiar os demais (MCLUHAN, 1972).

Por outro lado, quando essa rede sensória é esfriada, quando não há privilégio de um sentido dominante durante o uso de um meio, chega-se a um sobejo estado de alucinação. Ou seja, se em presença dos meios utiliza-se todas as sensações externas durante a experiência de fruição, a pessoa começa a preencher o espaço de percepção informativo em um processo alucinatório (MCLUHAN, 2012). 
Embora condicione a modificação dos sentidos humanos quando confrontados com os meios, o pensador canadense nunca simplifica essa relação em caráter unilateral. Isto é, ele não condiciona os meios como os dominantes da relação e nem coloca os indivíduos como figuras passivas dispostas a acatar as decisões dos aparatos. Mais uma vez, é interessante assinalar que os meios, sendo extensões humanas, dependem dos usuários para interagir e evoluir em suas funcionalidades.

\section{A crítica sobre o pensamento mcluhaniano}

O estigma de carregar uma postura determinista sobre os efeitos da tecnologia, além de alternar uma escrita ora de caráter crítico, ora de posição otimística complica o modo de apropriação das ideias de McLuhan no contexto acadêmico. O fato de concentrar sua produção entre as décadas de 1950 e 1970 dificulta ampliar algumas de suas teorias para uma realidade tecnológica bastante diferente do cenário ao qual ele se reportava naquele período.

Repetidamente se questiona até que ponto a tecnologia se apresenta como a única protagonista do plano de formação de uma sociedade técnica, sem complexificar o papel das dimensões sociais e culturais envolvidas no esquema, além da apresentação histórica e política que possibilitou o progressivo desenvolvimento desse cenário tecnológico. Segundo Rüdiger (2011), o equívoco na formulação desse modelo interpretativo é supor que a comunicação pode ser estruturada tecnicamente, assim como conceber que o simbólico pode ser instituído por um viés estritamente técnico. Afinal, "as tecnologias em si não mediatizam a sociedade", e a comunicação se caracteriza como "mediação simbólica da práxis social que obedece a diferentes codificações” (RÜDIGER, 2011, p. 125).

A noção de que a tecnologia molda os acontecimentos sociais e culturais dos indivíduos parece sugerir um determinismo tecnológico. De acordo com Barbosa (2011), dois segmentos se formam dentro desse modelo de pensamento: o primeiro defende a tecnologia como agente decisivo para toda a condição humana, qualificando-se como um determinismo do tipo hard; já o segundo coloca a tecnologia como efeito da vontade humana e a analisa a partir de um contexto sócio-histórico específico, apresentando-se como um determinismo do tipo soft.

Um dos críticos mais ferrenhos em acusar o pensador canadense de determinista foi o antropólogo galês Raymond Williams. A sua argumentação contra a teoria mcluhaniana se direciona em dois sentidos, como relembra Pereira (2011, p. 182): o primeiro questiona o fato de McLuhan ignorar variáveis sociais, políticas e econômicas em suas análises, abrindo possibilidade para uma crença de uma "essência humana 
ideal" atingida, em última circunstância, por aspectos físicos que se traduziriam - como sugere McLuhan - em afetações neurofisiológicas.

O segundo questionamento, em continuidade ao que o anterior inquire, expõe a fragilidade do pensamento de McLuhan ao excluir a história do processo de afetação humana, o qual, aliás, se confirma como a verdadeira causa para a ocorrência de tal processo. Ou seja, "para Williams, pois, McLuhan isolou por completo uma ideia de humano e de meio abstraídos de um contexto sócio-histórico, como se a mídia pudesse operar e produzir seus efeitos nesse humano idealizado, de forma exclusiva" (Ibid., p. 184).

A mesma observação sobre o desprezo do contexto histórico é enfatizada por Tremblay (2003), que situa esse elemento como um pano de fundo apresentado sem importância na obra mcluhaniana. Ele ainda comenta sobre algumas passagens se reportarem a uma proposta mecânica e industrial da produção midiática, como "a divisão e hierarquização das operações, substituição dos componentes, reprodução mecânica, linearidade do pensamento" (TREMBLAY, 2003, p. 16).

Ao verificar os últimos escritos de McLuhan, observa-se uma suavidade do tom determinista, especialmente nos textos que serviram de base para a formação de seu livro póstumo, chamado Laws of Media, realizado em parceria com seu filho. Nesse material, lançado em 1988, oito anos após sua morte, reúne-se um estudo mais avançado sobre a compreensão de meio, entendido tanto como uma concepção de metáfora para se analisar o modo de apreensão das subjetividades e da cultura como também é visto a partir da noção de ambiente combinado aos contextos simbólicos e sociais da realidade à qual se faz presente.

O próprio McLuhan confrontava essas variações de leituras e brincava continuamente com elas, afirmando seu caráter polêmico de que não está nem como o proclamador do apocalipse, nem como o profeta das boas novas. Para ele, o que está aí serve muito mais como conhecimento da realidade posta do que o entusiasmo único às potencialidades oferecidas:

Muita gente parece pensar que, se você fala sobre alguma coisa recente, é porque é a favor dela. Todas as coisas sobre as quais falo são quase certamente coisas às quais sou absolutamente contrário, e parece-me que a melhor forma de me opor a elas é compreendê-las, pois então saberemos onde desligar o botão. (MCLUHAN, 2005, p. 142).

Contudo, na prática, se tecnologias são de fato meios de projeção da consciência, a verdade é que McLuhan parece ter superestimado as qualidades e subestimado os defeitos inevitáveis que também constituem o ser humano. Em outras palavras, a dimensão 
perversa da mente humana também se materializa nessas extensões tecnológicas. E é nesse sentido que surge o cinema de Cronenberg.

\section{Horror e tecnociência em Cronenberg}

Nos filmes de Cronenberg, a tecnologia não é abordada a partir da tradicional perspectiva do deslumbramento otimista, do encanto mágico desses aparelhos daquilo que Lipovetsky e Serroy (2011) chamaram de "humanismo prometeico". Ao contrário, o foco de seus filmes busca formular um contraponto sobre as implicações da tecnociência infiltrada nas relações humanas.

Quase toda a obra de Cronenberg é uma exploração menos do fato do mundo humano ter se tornado prisioneiro de todo o tipo de ficção engendrada pela ciência e tecnologia, mas a eventual necessidade de nos confrontarmos com nossos descalabros, bizarrias e estranhamentos. A paixão humana pela máquina é representada como problema ameaçador imanente e indissociável da nossa condição. (RÜDIGER, 2006, p. 53).

Para Cronenberg, como para McLuhan, é fundamental entender a tecnologia como uma extensão do ser humano e, consequentemente, a sua função de agente integrante tanto da própria matéria biológica como também de facilitadora de ações essenciais durante o desenvolvimento da interação humana dentro de um contexto social. Por meio da entrevista concedida ao editor Chris Wallace (2014), ele explica melhor seu ponto de vista:

Eu sempre vi a tecnologia como uma extensão de nós. Então faz sentido que a tecnologia torne-se parte de nós, retorne a nós. Nos anos 1950, um monte de ficção científica estava apresentando uma tecnologia desumanizada, mas realmente, nada é só humano, nem todas as melhores e piores partes de nós mesmos. Pense no maquinário de guerra que nós vemos todos os dias - ele é como nossa fantasia de poder tornada metalizada, mas é ainda a gente. Então, que a tecnologia deve infundir nossas vidas, direto em nossos corpos, é inevitável. Tão longe quanto nós podemos ver, civilização tem sido dessa forma. Mas porque ela vira mais sofisticada e mais ubíqua, começa a ser um facilitador de todos os aspectos de nossas vidas, incluindo sexo. (tradução nossa).

O convívio inseparável entre ser humano e máquina expresso em seus filmes revela o quanto essa união atinge diversas dimensões da experiência humana, seja social, comportamental ou identitária, como também demonstra a possibilidade de modificação da matéria orgânica quando esta se submete ao toque do artificial, em que o corpo passa por uma reconfiguração e se transforma em um novo ente. 
O sinal dessa mutação é o que Cronenberg classifica como o estatuto da nova carne, referenciado segundo a expressão "new flesh". Agora, tem-se um corpo amorfo, vulnerável e exposto ao agente tecnológico, sendo que essa nova matéria assume uma posição nunca antes evidenciada e altera o entendimento de quais atributos tornam reconhecível a estrutura física do corpo humano.

Um exame minucioso de sua filmografia possibilita verificar a repetição do tema corpo e tecnociência em algumas de suas obras. Em seus quatro primeiros longas-metragens - Stereo, Crimes do futuro, Calafrios e Enraivecida na fúria do sexo-, a técnica está representada pelas manipulações científicas que atingem o corpo dos personagens, provocando alterações em seus organismos que ora os colocam como ameaças sociais (como em Calafrios e Enraivecida na fúria do sexo), ora desencadeiam drásticas mudanças de comportamento capazes de elevar seus níveis de sexualidade e violência (retratado em Stereo e Crimes do futuro).

A sequência fílmica (Filhos do medo e Scanners) continua repetindo a temática da simbiose entre homem e tecnologia pelo mesmo enfoque do envolvimento das intervenções científicas na transformação da estrutura corpórea. Médicos e cientistas são personagens de destaques em todas as suas obras iniciais, reforçando o caráter da ciência como um campo de problematização propício para desencadear o surgimento de seres híbridos ou redimensionados pelas inserções técnicas.

Porém, é na sua obra seguinte, Videodrome, que o diretor atinge o ápice dessa discussão ao retratar a fusão entre tecnologia e sujeito a partir de uma contextualização mais próxima do nosso cotidiano. As atenções ficam dirigidas para as mídias eletrônicas que aparecem como extensores amalgamados do corpo, com capacidade de condicionar alteridades sobre a percepção sensória humana.

De forma intencional, reverberando ideias de McLuhan, Cronenberg assume que o roteiro se baseia em abordar a tecnologia como elemento de enunciação alucinatória ou hipnótica para os indivíduos, questionando os efeitos provocados por essa contínua exposição.

Com Videodrome, eu queria colocar a possibilidade de que um homem exposto a imagens violentas começaria a alucinar. [...] Mas existe a sugestão de que a tecnologia envolvida em Videodrome é especificamente designada a criar violência na pessoa; nós sabemos que o uso de eletrodos em certas áreas do cérebro pode desencadear violência, resposta temível sem levar em conta outros estimulantes. (RODLEY, 1997, p. 94, tradução nossa).

A ideia inicial do roteiro é descrita por Cronenberg como uma recordação que tinha da infância quando assistia à televisão tarde da noite e algumas estações saiam 
e voltavam do ar. As imagens indefinidas o deixavam curioso sobre de onde elas vinham e qual seu significado, repercutindo em sua mente como um reduto misterioso a ser explorado. Acrescida à incógnita, há uma combinação de influências do pensamento mcluhaniano que, assim como nota, foi decisiva para o argumento inicial da obra (GRÜNBERG, 2006).

$\mathrm{O}$ roteiro totalmente original de Videodrome trabalha com a premissa de um misterioso programa de televisão que é transmitido de forma ilegal e exibe imagens de pessoas sendo torturadas e obrigadas a fazer sexo com requintes de crueldade. $\mathrm{O}$ grau exagerado de realismo das situações passadas pelos participantes cria uma desconfiança de que nada no programa é simulado, mas que de fato tudo que ali se passa realmente acontece com os envolvidos nas cenas.

Curioso a esse respeito, o dono de uma pequena emissora de televisão e direcionada à exibição de conteúdos pornográficos, Max Renn (interpretado pelo ator James Woods), começa a ficar interessado pelas imagens perturbadoras e decide conhecer de perto o ambiente e os realizadores por trás de Videodrome. O envolvimento nesse espetáculo grotesco começa a alterar de forma incisiva o seu sentido de percepção das instâncias de realidade, em que não mais se identifica as ações originadas fora ou dentro do espectro televisivo. Em outras palavras, o efeito alucinatório cria uma percepção híbrida entre ficção mediatizada e realidade.

Além disso, a aproximação do personagem com o Videodrome destaca a dimensão do meio eletrônico em funcionar como uma extensão da matéria orgânica. À medida que se intensificam as alucinações do personagem Max, observa-se o quanto ele mesmo se enxerga como o próprio aparelho de vídeo, a ponto de tragar uma fita dentro de sua barriga e estabelecer uma relação corpórea com o televisor.

Dessa forma, Cronenberg mais uma vez proclama o surgimento da "nova carne", a partir do encontro entre corpo e máquina. Essa junção no filme não só anuncia a formação de um novo envoltório físico, como também mostra a interferência dos meios nos padrões vinculados à identidade dos indivíduos e a descaracterização da experiência subjetiva intermediada e estendida para dentro do ambiente midiático.

Eu não acredito que alguém está no controle. Aquilo é o que McLuhan estava falando sobre a razão de termos que entender a mídia, porque se nós não fazemos isso, ela irá nos controlar. Nós não temos que antropomorfizar a mídia e dizer que ela irá nos controlar. A mídia não tem um cérebro; ela é justamente tecnologia. O que significa é que as coisas estão fora de controle. Ninguém está no controle. Existe somente a aparência de controle. Eu sinto a desordem muito 
próxima, que é uma das razões, eu suponho, de eu me sentir excluído, simplesmente porque eu penso estar mais consciente da presença e proximidade do caos (RODLEY, 1997, p. 67, tradução nossa).

Após o lançamento de Videodrome, no início da década de 1980, o diretor canadense ainda realiza outros filmes voltados à temática do homem e tecnologia nos anos posteriores. Porém, nenhum deles apresenta uma nova abordagem sobre o entendimento das tecnologias midiáticas em confluência com os sujeitos. Somente no último ano da década de 1990 é que mais uma vez será dada atenção ao assunto, a partir de um roteiro concebido por uma inspiração pessoal de Cronenberg.

A obra, eXistenZ (1999), constitui-se como um projeto herdeiro de Videodrome não só por destacar o mesmo tipo de objeto tecnológico e a sua conjuntura de relacionamento com o indivíduo, mas também por reiterar um sistema de tensão exercido pelo aparelho midiático possível de alterar a capacidade sensória e subjetiva dos seres.

Nesse momento, fica clara a retomada dos conceitos de McLuhan já expostos pelo diretor em Videodrome, que acabam se reconfigurando, porém, em uma dimensão que sai da esfera televisiva e vai para o meio digital. Com mais essa obra, Cronenberg confirma que intencionalmente se apropria das concepções do pensador canadense para formar sua posição de como compreende a inserção da tecnologia no meio social. E à sua maneira, contribui para refletir sobre os "esforços tecnocientíficos em produzir uma resolução técnica para o mal-estar do homem e de sua cultura" (PINHEIRO; CARNEIRO, 2013, p. 420).

\section{Considerações finais}

Obras cinematográficas carregam marcas evidentes de seu contexto de produção. Ao operar escolhas, relacionar elementos e tecer vínculos complexos com a realidade, o filme pode se apresentar ora como um reflexo, ora como uma recusa do real, ocultando certos aspectos, ampliando os defeitos ou propondo uma alternativa. Mas o fato é que, em qualquer uma dessas circunstâncias, o filme se configura como um ponto de vista sobre um aspecto do mundo na sua contemporaneidade.

Sem cair na armadilha de "ler" na obra de Cronenberg toda a sociedade e a história da emergência das tecnologias no passado, no presente e no futuro, observa-se que o cineasta canadense, cuja obra é nitidamente influenciada pela Escola de Toronto, criou metáforas seminais para problematizar a reflexão sobre a dinâmica ser humano-tecnociência.

Se as tecnologias, como afirma McLuhan, são prolongamentos dos nossos órgãos e, em última instância, projetam os nossos sentidos e a nossa consciência, tornando-se 
enfim as expressões do nosso próprio ser, todo o lado sombrio, que necessariamente constitui parte de nosso ser - e que frequentemente é reprimido e jogado nas sombras do inconsciente - não deixa de estar igualmente presente nessas extensões, integrando-as, constituindo-as e preenchendo-as de sentido (conscientemente ou não). Daí a metáfora dos aparatos tecnológicos que sangram, expelem secreções e transformam a consciência humana em um pesadelo.

Nesse sentido, ao ocupar aquela fronteira híbrida entre ficção e realidade, entre a tecnologia e o orgânico, e, por fim, entre a máquina e o indivíduo, as extensões tecnológicas do corpo e da mente no cinema de Cronenberg revelam um caráter igualmente ambíguo da tecnociência, que se revela em artefatos que, ao mesmo tempo, não são, por si só, nem bons, nem maus, nem neutros: são dinâmicos, pois ao mesmo tempo que são reflexos dos sonhos e pesadelos já existentes na mente humana, interferem de forma dialética na mente desse mesmo humano, seja como uma tecnologia que altera percepções sensoriais, intensifica o uso com estímulos artificiais - e, como consequência, anestesia outros sentidos -, seja como um artefato em que todas as sensações são estimuladas até a mais completa alucinação - ocasião em que a realidade virtual se torna orgânica, biológica, sensorial.

Assim como McLuhan, Cronenberg evidencia a simbiose entre indivíduo e máquina por uma associação indissociável e mutuamente influenciável, em que nem humano nem técnica se qualificam em um papel figurante ou passivo nessa troca. Mas ainda que afirme essa relação, para ele, não há como instituir um controle desse processo. No cinema de Cronenberg, a desordem e o caos são inevitáveis, mesmo que o ser humano se entregue a ilusões de controle.

Para ambos, humano e máquina sempre estiveram indissociados. Nesse sentido, a tecnologia é uma extensão fundamental para o desenvolvimento das ações humanas em um contexto social. Assim, o meio é realmente mensagem na filmografia de Cronenberg. Mas, em um contraste a McLuhan, Cronenberg propõe uma conotação niilista desse aforismo, pois a mensagem da máquina, além de não harmonizar as incoerências do sujeito contemporâneo, ainda reafirma e potencializa, de maneira intensa e brutal, as contradições ainda não resolvidas da natureza humana, como as perversidades secretas, as fantasias violentas e o próprio descontrole interior de sujeitos que negligenciam a busca pela autoconsciência e delegam às máquinas o papel de resolver os problemas humanos.

\section{Referências}

BARBOSA, R. McLuhan e as críticas. In: CONGRESSO BRASILEIRO DE CIÊNCIAS DA COMUNICAÇÃO, 34., 2011, Recife. Anais eletrônicos... Recife: Unicap, 2011. p. 1-15. 
Disponível em: <http://www.intercom.org.br/papers/nacionais/2011/resumos/R6-2386-1.pdf . Acesso em: 30 abr. 2015.

BREDER, D. David Cronenberg: a "inquietante estranheza". Revista Alceu, Rio de Janeiro, v. 11, n. 22, p. 174-193, 2011. Disponível em: <http://revistaalceu.com.puc-rio.br/media/Artigo10\%20 Debora\%20Breder\%20-\%20pp174-193.pdf>. Acesso em: 3 fev. 2015.

ERNST, T. Talking to David Cronenberg. Toro magazine, Toronto, abr. 2009. Disponível em: $<$ http://toromagazine.com/features/talking-to/20090428/david-cronenberg>. Acesso em: 15 set. 2015.

GRÜNBERG, S. David Cronenberg: interviews with Serge Grünberg. London: Plexus, 2006.

INNIS, H. A. Empire and communications. Oxford: Oxford University Press, 1950.

. The bias of communication. Toronto: University of Toronto Press, 1951.

LIPOVETSKY, G.; SERROY, J. A cultura-mundo: resposta a uma sociedade desorientada. São Paulo: Companhia das Letras, 2011.

MARCONDES FILHO, C. (Org.). Dicionário de comunicação. São Paulo: Paulus, 2009.

MCLUHAN, M . Os meios são as massa-gens. Tradução Ivan Pedro de Martins. 2. ed. Rio de Janeiro: Record, 1969.

. A galáxia de Gutenberg: a formação do homem tipográfico. Tradução Leônidas Gontijo de Carvalho e Anísio Teixeira. São Paulo: Nacional, 1972.

. Entrevista com Herbert Marshall Mcluhan. In: CASASÚS, J. M. (Org.). Teoria da imagem. Tradução Nestor de Sousa. Rio de Janeiro: Salvat, 1979. p.

In: MCLUHAN, S.; STAINES, D. (Orgs.). McLuhan por McLuhan: entrevistas e conferências inéditas do profeta da globalização. Tradução Antonio de Padua Danesi. Rio de Janeiro: Ediouro, 2005. Os meios como extensões do homem. Tradução Décio Pignatari. 18. ed. São Paulo: Cultrix, 2012.

PEREIRA, V. A. Estendendo McLuhan: da aldeia à teia global - comunicação, memória e tecnologia. Porto Alegre: Sulina, 2011.

PINHEIRO, R.; CARNEIRO, H. F. A fascinação pelo resto: o hiper mal-estar na tecnociência. Tempo psicanalítico, Rio de Janeiro, v. 45, n. 2, p. 419-438, 2013. Disponível em: <http://pepsic.bvsalud. org/scielo.php?script=sci_arttext\&pid=S0101-48382013000200011\&lng=pt\&nrm=iso $>$. Acesso em: 24 out. 2015.

RODLEY, C. Cronenberg on Cronenberg. London: Faber and Faber, 1997.

RÜDIGER, F. A dialética entre homem e máquina no cinema contemporâneo: de Kubrick a Spielberg, via Omega man, Blade Runner e Dark City. Revista Logos, Rio de Janeiro, v. 1. n. 24, p. 51-67, 2006. Disponível em: <http://www.logos.uerj.br/PDFS/24/5_rudiger.pdf>. Acesso em: 10 fev. 2015. . As teorias da comunicação. Porto Alegre: Penso, 2011.

SOUSA, J. P. Elementos de teoria e pesquisa da comunicação e dos media. 2. ed. Porto: BOCC, 2006. 
TREMBLAY, G. De Marshall McLuhan a Harold Innis ou da Aldeia Global ao Império Mundial. Famecos, Porto Alegre, n. 22, p. 13-22, dez. 2003. Disponível em: <http://revistas.univerciencia.org/index. php/famecos/article/viewFile/228/173>. Acesso em: 15 mar. 2015.

VANOYE, F.; GOLIOT-LÉTÉ, A. Ensaio sobre a análise filmica. Campinas: Papirus, 1994.

WALLACE, C. David Cronenberg. Interview, New York, 10 out. 2014. Disponível em: <http://www.interviewmagazine.com/film/david-cronenberg/\#page2>. Acesso em: 24 jul. 2015.

$86 \frac{\text { Comunicação \& Inovação, PPGCOM/USCS }}{\text { v. 17, n. } 35 \text { (70-86) set-dez } 2016}$ 